\title{
What are Canadian primary care physicians prescribing for the treatment of gonorrhea?
}

\author{
S Ha ${ }^{1}$, L Pogany ${ }^{2}$, J Seto ${ }^{3}$, J Wu ${ }^{4}$, M Gale-Rowe ${ }^{4 *}$
}

\begin{abstract}
Background: Cases of Neisseria gonorrhea are on the rise in Canada, which-if undetected or undertreated-can lead to morbidity and infertility. In addition, the number of antimicrobial resistant strains is also increasing creating the risk that $N$. gonorrhea may become untreatable. In 2013, the Public Health Agency of Canada (PHAC) released Canadian recommendations for the management and treatment of gonorrhea that identified the need for combination therapy to address and minimize antimicrobial resistance. However, the level of awareness and uptake of these guidelines is not well-known.
\end{abstract}

Objectives: To assess primary care physicians' prescribing practices for the management and treatment of gonorrhea.

\begin{abstract}
Methods: After validity testing, two online cross-sectional surveys were conducted with a convenience sample of Canadian physicians. Physicians answered true/false statements and open-ended questions relating to three clinical scenarios: 1) suspected anogenital infection drawing from a population of men who have sex with men (MSM); 2) suspected anogenital infection drawing from a non-MSM population; and, 3) suspected pharyngeal infection drawing from any population. Frequencies of responses were calculated for the statements. Open-ended responses were recoded into treatment categories and frequencies were calculated for each scenario.
\end{abstract}

Results: A total of 625 physicians completed the survey. Most physicians (60\%-95\%) accurately identified knowledge statements regarding pharmaceutical management, partner notification and public health reporting. For all clinical scenarios, $30 \%-35 \%$ of physicians did not provide any treatment information, approximately $30 \%$ indicated treating with cephalosporin monotherapy, $20 \%-25 \%$ indicated they would prescribe a cephalosporin and azithromycin and a minority of physicians identified other treatment options. When physicians were asked about the purpose of the second antibiotic, azithromycin, $49 \%$ indicated it was to provide presumptive treatment for gonorrhea and chlamydia. Forty-one percent indicated it was to provide presumptive treatment for chlamydia only.

Conclusion: This convenience sample suggests that although knowledge of pharmaceutical management, partner notification, and public health reporting is high, the use of combination therapy to deter the development of antimicrobial resistant gonorrhea may not be widespread among primary care physicians. In light of both the growing incidence of $N$. gonorrhea and the rising rates of antimicrobial resistance in Canada, consideration on how to improve awareness and uptake of best prescribing practices in primary care may be indicated.

\section{Affiliations}

${ }^{1}$ Health Products and Food Branch, Health Canada, Ottawa, ON

${ }^{2}$ Regulatory Operations and Regions Branch, Health Canada, Ottawa, ON

${ }^{3}$ Global Affairs Canada, Ottawa, $\mathrm{ON}$

${ }^{4}$ Centre for Communicable Diseases and Infection Control, Public Health Agency of Canada, Ottawa, ON *Correspondence: margaret.
gale-rowe@phac-aspc.gc.ca

Suggested citation: Ha S, Pogany L, Seto J, Wu J, Gale-Rowe M. What are Canadian primary care physicians prescribing for the treatment of gonorrhea? Can Commun Dis Rep. 2017;43(2):33-7.

https://doi.org/10.14745/ccdr.v43i02a01

\section{Introduction}

Gonococcal infection, caused by Neisseria gonorrhea, is a growing clinical and public health issue due to increasing rates, patterns of antimicrobial resistance and its association with long term health sequelae when left untreated or treated ineffectively. Among women, untreated gonorrhea is associated with pelvic inflammatory disease, ectopic pregnancy, or infertility; among men, it is associated with epididymitis or infertility $(1,2)$. In Canada, reported cases of gonorrhea have increased by $38.9 \%$ between 2003 and 2012, with rates highest among 20-24-year-old men (148.5 per 100,000) and women (153.0 per 100,000) (3).
In addition to rising rates of gonorrhea, antimicrobial resistant $N$. gonorrhea has been increasing (4) including strains resistant to ceftriaxone (5). The Government of Canada has identified antimicrobial resistance as a priority area for action, and in 2013, the Public Health Agency of Canada (PHAC) released updated recommendations for the treatment of gonorrhea in their Canadian Guidelines on Sexually Transmitted Infections. These guidelines recommend combination antibiotic therapy, with the choice of medications varying by population and site of infection $(6,7)$ (Table 1). Combination antibiotic therapy is recommended as the preferred therapy. It provides treatment with antibiotics acting through two different mechanisms which reduces the likelihood of treatment failure, addresses the emergence of 
multi-drug resistant gonorrhea, and provides effective treatment for chlamydia (8-12). However, other guidelines are available and may inform the practice of primary care physicians.

\section{Table 1: Canadian Guidelines on Sexually Transmitted Infections 2013 recommendations for the treatment of uncomplicated gonorrhea}

\begin{tabular}{|c|c|c|}
\hline Scenario & $\begin{array}{l}\text { Preferred } \\
\text { therapy }\end{array}$ & Alternate therapy \\
\hline $\begin{array}{l}\text { Non-MSM adults } \\
\text { and youth ( } \geq 9 \\
\text { years of age) with } \\
\text { uncomplicated } \\
\text { anogenital infection }\end{array}$ & $\begin{array}{l}\text { Ceftriaxone } \\
\text { 250mg IM PLUS } \\
\text { azithromycin 1g PO } \\
\text { OR } \\
\text { Cefixime } 800 \mathrm{mg} \\
\text { PLUS azithromycin } \\
\text { 1g PO }\end{array}$ & $\begin{array}{l}\text { Spectinomycin } 2 \mathrm{~g} \text { IM PLUS } \\
\text { azithromycin } 1 \mathrm{~g} \\
\text { OR } \\
\text { Azithromycin } 2 \mathrm{~g} P O\end{array}$ \\
\hline $\begin{array}{l}\text { Non-MSM adults } \\
\text { and youth ( } \geq 9 \\
\text { years of age) with } \\
\text { uncomplicated } \\
\text { pharyngeal infection }\end{array}$ & $\begin{array}{l}\text { Ceftriaxone } \\
\text { 250mg IM PLUS } \\
\text { azithromycin 1g PO }\end{array}$ & $\begin{array}{l}\text { Cefixime } 800 \mathrm{mg} \text { PO PLUS } \\
\text { azithromycin } 1 \mathrm{~g} \text { PO } \\
\text { OR } \\
\text { Azithromycin } 2 \mathrm{~g} \text { PO }\end{array}$ \\
\hline $\begin{array}{l}\text { Men who have sex } \\
\text { with men (MSM) } \\
\text { with uncomplicated } \\
\text { anogenital infection }\end{array}$ & $\begin{array}{l}\text { Ceftriaxone } 250 \mathrm{mg} \\
\text { intramuscularly (IM) } \\
\text { PLUS azithromycin } \\
1 \mathrm{~g} \text { orally (PO) }\end{array}$ & $\begin{array}{l}\text { Cefixime } 800 \mathrm{mg} \text { PO PLUS } \\
\text { azithromycin } 1 \mathrm{~g} \text { PO } \\
\text { OR } \\
\text { Spectinomycin } 2 \mathrm{~g} \text { IM PLUS } \\
\text { azithromycin } 1 \mathrm{~g} \text { PO } \\
\text { OR } \\
\text { Azithromycin } 2 \mathrm{~g} \text { PO }\end{array}$ \\
\hline $\begin{array}{l}\text { MSM with } \\
\text { uncomplicated } \\
\text { pharyngeal infection }\end{array}$ & $\begin{array}{l}\text { Ceftriaxone } \\
250 \mathrm{mg} \text { IM PLUS } \\
\text { azithromycin 1g PO }\end{array}$ & $\begin{array}{l}\text { Cefixime } 800 \mathrm{mg} \text { PO PLUS } \\
\text { azithromycin } 1 \mathrm{~g} \text { PO }\end{array}$ \\
\hline
\end{tabular}

Findings from Canadian sexual health clinics suggest that combination therapy is prescribed at least $76 \%$ of the time (13), however, there is a paucity of evidence documenting primary care physicians' prescribing practices. Primary care health professionals have an important role in the prevention and management of antimicrobial resistant gonorrhea.

The objectives of the study were to describe primary care physicians' knowledge related to the management of antimicrobial resistant (AMR) gonorrhea and to identify their prescribing preference for three clinical scenarios.

\section{Methods}

\section{Survey}

PHAC commissioned two online cross-sectional surveys from an online survey company who recruits physicians across Canada who agree to be contacted for surveys. In April 2014 and March 2015, participating physicians were invited to take a 20-minute online survey with both open- and closed-ended questions. Survey questions were derived from previously developed questionnaires and were tested for face validity with PHAC nurses, physicians and epidemiologists. Physicians were asked to answer 14 true/false statements regarding the epidemiology, diagnosis, management and public health reporting of AMR gonorrhea. Open-ended responses for three clinical scenarios were solicited: 1) Suspected anogenital infection drawing from a population of MSM; 2) suspected anogenital infection drawing from a non-MSM population; and 3) suspected pharyngeal infection drawing from any population. Physicians received a financial incentive for completing the survey.
In 2015, a question was added to clarify physicians' reasons for prescribing the second antibiotic, azithromycin, for the treatment of gonorrhea.

\section{Data analysis}

Data were analyzed using SAS EG (v5.1). Pearson's chi-square test was used to compare the two samples. The datasets from both survey cycles were combined for analysis because no differences were found between the sample populations. The frequency of correct responses was calculated for each of the true/false statements on the diagnosis, treatment, follow-up and public health reporting of gonorrhea. The open-ended responses for the three clinical scenarios were recoded into the following treatment options: ceftriaxone and azithromycin; cefixime and azithromycin; cephalosporin alone; azithromycin alone; spectinomycin with azithromycin and other pharmaceutical regimens. Dosing information and route of administration were not considered due to large amounts of missing data. Physicians who indicated "not applicable", "do not treat men", "not sure", or "don't know" were grouped under "no treatment information".

\section{Results}

A total of 2500 physicians were contacted for the first survey and 321 completed the survey for a response rate of $13 \%$. A total of 3600 physicians were contacted for the second survey and 304 completed the survey for a response rate of eight percent. $A$ total of 625 physicians completed the two surveys.

\section{Physicians' demographics and characteristics}

Two thirds of respondents were male (66\%), $83 \%$ of physicians had 10 or more years of practice and $85 \%$ worked in family medicine. Almost $75 \%$ of respondents encountered at least one case of gonorrhea in the previous year (Table 2).

Table 2: Socio-demographic characteristics of respondents $(\mathrm{N}=625)$

\begin{tabular}{|c|l|l|}
\hline \multicolumn{2}{|c|}{ Characteristic } & \multicolumn{1}{c|}{ N $\%)$} \\
\hline Sex & 208 & $33 \%$ \\
\hline Female & 410 & $66 \%$ \\
\hline Male & 7 & $1 \%$ \\
\hline Prefer not to disclose & \multicolumn{2}{l|}{} \\
\hline Years of practice (years) & 109 & $17 \%$ \\
\hline Less than 10 & 516 & $83 \%$ \\
\hline 10 or more & \multicolumn{2}{l|}{} \\
\hline Profession & 532 & $85 \%$ \\
\hline Family medicine & 60 & $10 \%$ \\
\hline Obstetrics/gynecology & 21 & $3 \%$ \\
\hline Emergency medicine & 12 & $2 \%$ \\
\hline Other & \multicolumn{2}{|l|}{} \\
\hline Practice setting 1 & 502 & $80 \%$ \\
\hline General/family practice & 73 & $12 \%$ \\
\hline Community health centre & 206 & $33 \%$ \\
\hline Walk-in clinic/urgent care & 67 & $11 \%$ \\
\hline Sexual health clinic &
\end{tabular}


Table 2: Socio-demographic characteristics of respondents $(\mathrm{N}=625)$ (continued)

\begin{tabular}{|l|r|r|}
\hline \multicolumn{1}{|c|}{ Characteristic } & N & (\%) \\
\hline Practice setting (continued) & \\
\hline Student health services & 31 & $5 \%$ \\
\hline Emergency & 26 & $4 \%$ \\
\hline Obstetrics/gynecology clinic & 14 & $2 \%$ \\
\hline Other & 36 & $6 \%$ \\
\hline Number of cases of gonorrhea encountered in the past year \\
\hline 0 & 153 & $25 \%$ \\
\hline 1 & 90 & $14 \%$ \\
\hline $2-4$ & 169 & $27 \%$ \\
\hline $5-9$ & 97 & $16 \%$ \\
\hline $10+$ & 104 & $17 \%$ \\
\hline Not sure/no response & 12 & $2 \%$ \\
\hline
\end{tabular}

Abbreviations: N, Number; \%, percentage

1 Percentages do not add to $100 \%$ as physicians may practice in more than one setting. Denominator is the total sample size

\section{Knowledge related to the management of antimicrobial resistant gonorrhea}

Overall, $60 \%$ to $95 \%$ of physicians accurately identified knowledge statements regarding pharmaceutical management, partner notification and public health reporting. Approximately two thirds of the respondents accurately identified statements related to current trends in rising incidence, the most common age groups affected and the presence of antimicrobial resistant gonorrhea in Canada (Table 3). Most respondents (87\%) identified the importance of co-treatment for chlamydia.

Table 3: Knowledge statements for the public health management of antimicrobial resistant gonorrhea

\begin{tabular}{|c|c|c|}
\hline $\begin{array}{c}\text { Area } \\
\text { assessed }\end{array}$ & Knowledge statement & $\begin{array}{l}\mathbf{N}(\%) \\
\text { correct }\end{array}$ \\
\hline \multirow[t]{3}{*}{ Epidemiology } & $\begin{array}{l}\text { The number of reported cases of gonorrhea } \\
\text { infection has decreased in the last decade or } \\
\text { so. (True) }\end{array}$ & 384 (61\%) \\
\hline & $\begin{array}{l}\text { Antibiotic resistant gonorrhea is not a } \\
\text { problem in Canada. (False) }\end{array}$ & 400 (64\%) \\
\hline & $\begin{array}{l}\text { Gonorrhea is the most commonly found in } \\
30-40 \text { year old females. (False) }\end{array}$ & 316 (51\%) \\
\hline \multirow[t]{4}{*}{ Diagnostic testing } & $\begin{array}{l}\text { Follow-up test of cure should be completed } \\
\text { on all cases of diagnosed gonorrhea if } \\
\text { possible. (True) }\end{array}$ & 445 (71\%) \\
\hline & $\begin{array}{l}\text { Cultures are particularly important for MSM } \\
\text { who are symptomatic. (True) }\end{array}$ & $413(66 \%)$ \\
\hline & $\begin{array}{l}\text { When gonorrhea infection is suspected, } \\
\text { samples should be taken from symptomatic } \\
\text { patients and sent for both cultures and } \\
\text { NAAT. (True) }\end{array}$ & $350(56 \%)$ \\
\hline & $\begin{array}{l}\text { Patients who fail treatment should have } \\
\text { repeated NAAT testing. (False) }\end{array}$ & $82(13 \%)$ \\
\hline \multirow[t]{3}{*}{$\begin{array}{l}\text { Pharmaceutical } \\
\text { management }\end{array}$} & $\begin{array}{l}\text { Co-treatment for chlamydia is advisable } \\
\text { when treating for gonorrhea. (True) }\end{array}$ & $542(87 \%)$ \\
\hline & $\begin{array}{l}\text { It is necessary to wait for culture results prior } \\
\text { to antibiotic treatment of gonorrhea cases. } \\
\text { (False) }\end{array}$ & $492(79 \%)$ \\
\hline & $\begin{array}{l}\text { Patients presenting with gonorrhea should } \\
\text { be treated with a combination therapy. (True) }\end{array}$ & $374(60 \%)$ \\
\hline
\end{tabular}

Table 3: Knowledge statements for the public health management of antimicrobial resistant gonorrhea

(continued)

\begin{tabular}{|l|l|c|}
\hline Area assessed & \multicolumn{1}{|c|}{ Knowledge statement } & $\begin{array}{c}\text { N (\%) } \\
\text { correct }\end{array}$ \\
\hline Partner notification & $\begin{array}{l}\text { It is important to do partner notification } \\
\text { back to 60 days in all cases of diagnosed } \\
\text { gonorrhea. (True) }\end{array}$ & 542 (87\%) \\
\cline { 2 - 3 } & $\begin{array}{l}\text { Public health units can help physicians do } \\
\text { partner notification. (True) }\end{array}$ & 593 (95\%) \\
\hline $\begin{array}{l}\text { Public Health } \\
\text { Reporting }\end{array}$ & $\begin{array}{l}\text { Gonorrhea is a reportable infection. Local } \\
\text { public health authorities should be promptly } \\
\text { notified. (True) }\end{array}$ & 595 (95\%) \\
\cline { 2 - 3 } & $\begin{array}{l}\text { Gonorrhea is not a reportable infection in } \\
\text { Canada. (False) }\end{array}$ & $463(74 \%)$ \\
\hline
\end{tabular}

Abbreviations: MSM, Men who have sex with men; NAAT, Nucleic Acid Amplification Test; N, Number; \%, percentage

An additional question on the reason for prescribing a second antibiotic was added in the 2015 survey, and 49\% identified it was for presumptive treatment for both gonorrhea and chlamydia and $41 \%$ identified it was for presumptive treatment for chlamydia (Figure 1).

Figure 1: Family physicians' reasons for prescribing the second antibiotic for the treatment of gonorrhea (2015)

\begin{tabular}{|c|c|}
\hline $2 \% \Gamma^{1 \%}$ & $\begin{array}{l}\text { Presumptive treatment } \\
\text { for gonorrhea and } \\
\text { chlamydia ( } n=149 \text { ) } \\
\text { Presumptive treatment } \\
\text { for chlamydia only } \\
\text { ( } n=124) \\
\text { Provide augmented } \\
\text { treatment for AMR } \\
\text { gonorrhea only ( } n=21 \text { ) } \\
\text { Provide treatment for } \\
\text { cases of gonorrhea } \\
\text { treatment failure }(n=5) \\
\text { Other }(n=2)\end{array}$ \\
\hline
\end{tabular}

\section{Physicians' prescribing practices}

Table 4 summarizes the data for prescribing practices. For all clinical scenarios, $30 \%-35 \%$ of physicians did not provide any treatment information, approximately $30 \%$ of physicians indicated treating with cephalosporin monotherapy, $20 \%-25 \%$ indicated they would prescribe a cephalosporin and azithromycin; and a minority of physicians identified other treatment options.

As regards to MSM patients presenting with suspected anogenital infection, almost $30 \%$ of physicians did not identify any treatment options, almost $30 \%$ indicated they would prescribe cephalosporin alone, $25 \%$ indicated they would prescribe a cephalosporin and azithromycin, five percent identified azithromycin alone and the rest identified other treatment options. With respect to non-MSM patients presenting with uncomplicated gonorrhea anogenital infection, $30 \%$ of physicians reported using cephalosporin monotherapy, $25 \%$ reported combination therapy with a cephalosporin and azithromycin; eight percent indicated treating with azithromycin alone and $13 \%$ reported using other antibiotic regimens. For the treatment of patients with pharyngeal infection, slightly over 
$30 \%$ of physicians did not identify a treatment, $27 \%$ identified cephalosporin monotherapy, almost $20 \%$ identified combination therapy with a cephalosporin and azithromycin and 15\% of physicians reported using other pharmaceutical management strategies.

Table 4: Physicians' intent to prescribe for three clinical scenarios

\begin{tabular}{|c|c|c|c|}
\hline $\begin{array}{l}\text { Reported } \\
\text { treatment } \\
\text { choices }\end{array}$ & $\begin{array}{c}\text { MSM } \\
\text { anogenital } \\
\text { n (\%) }\end{array}$ & $\begin{array}{c}\text { Non-MSM } \\
\text { anogenital } \\
n(\%)\end{array}$ & $\begin{array}{l}\text { Pharyngeal } \\
\text { infection } \\
n(\%)\end{array}$ \\
\hline $\begin{array}{l}\text { Ceftriaxone + } \\
\text { Azithromycin }\end{array}$ & $81(13.0 \%)^{1}$ & $74(11.8 \%)^{1}$ & $68(10.9 \%)^{1}$ \\
\hline $\begin{array}{l}\text { Cefixime }+ \\
\text { Azithromycin }\end{array}$ & $72(11.5 \%)^{2}$ & $84(13.4 \%)^{1}$ & $53(8.5 \%)^{2}$ \\
\hline Azithromycin & $34(5.4 \%)^{2}$ & $50(8.0 \%)^{2}$ & $53(8.5 \%)^{2}$ \\
\hline $\begin{array}{l}\text { Spectinomycin + } \\
\text { Azithromycin }\end{array}$ & $0(0.0 \%)^{2}$ & $0(0.0 \%)^{2}$ & $0(0.0 \%)$ \\
\hline Cephalosporin only ${ }^{1}$ & $179(28.6 \%)$ & $186(29.8 \%)$ & 167 (26.7\%) \\
\hline Other $^{2}$ & $82(13.1 \%)$ & 84 (13.4\%) & 93 (14.9\%) \\
\hline $\begin{array}{l}\text { No treatment } \\
\text { information }\end{array}$ & 177 (28.3\%) & 147 (23.5\%) & $191(30.6 \%)$ \\
\hline
\end{tabular}

\section{Discussion}

These online surveys found that participating physicians were knowledgeable about the pharmaceutical management, partner notification, and public health reporting of N. gonorrhea, but appeared to be less knowledgeable about the use of combination therapy to deter the development of antimicrobial resistant gonorrhea. Approximately $25 \%$ reported their intent to prescribe the specific combination therapy for anogenital infection identified by the Canadian Guidelines on Sexually Transmitted Infections as the preferred therapy to prevent treatment failure and to mitigate the development of antimicrobial resistance. Responding physicians appeared to be less confident in prescribing for pharyngeal gonorrhea. These findings are in contrast to studies of sexual health clinics, where prescribing combination therapy is routine (14-17).

Monotherapy for the treatment of gonorrhea is not recommended as treatment failures with oral cefixime monotherapy have been documented in Canada $(12,18,19)$. In our sample, approximately $30 \%$ of physicians indicated they would treat gonorrhea with a cephalosporin monotherapy; however, close to half of physicians reported the purpose of the second antibiotic (often azithromycin) was for chlamydia only (and not gonorrhea) and $87 \%$ believed that co-treatment for chlamydia is advisable when treating for gonorrhea. As such, it is hypothesized that primary care physicians may be prescribing combination therapy, but largely to cover possible co-infection.

There are some limitations to consider. The response rate was very low and this convenience sample may not be representative of primary care physicians in Canada. In addition, a few of the questions may not have been clear and physicians' answers to epidemiological or diagnostic statements may have been consistent with their local epidemiology and guidelines, but not with national statistics or the Canadian Guidelines on Sexually Transmitted Infections.

\section{Conclusion}

In light of the rising incidence of gonorrhea and AMR gonorrhea, increasing awareness and uptake by primary care physicians of the routine use of combination therapy may help minimize treatment failure and deter the development of AMR gonorrhea.

\section{Acknowledgements}

We would like to thank the Expert Working Group for the Canadian Guidelines on Sexually Transmitted Infections for their contributions.

\section{Conflict of interest}

None.

\section{Funding}

This work was supported by the Public Health Agency of Canada. The authors have no external sources of funding to declare.

\section{References}

1. Creighton S. Gonorrhea. Am Fam Physician. 2012;85(6):642643.

2. Miller K. Diagnosis and treatment of Nessieria gonorrhoeae infections. Am Fam Physician. 2006;73(10):1779.

3. Totten S, MacLean R, Payne E. Gonorrhea in Canada: 20032012. Can Comm Dis Rep. 2015;41(2). Available from: http:// www.phac-aspc.gc.ca/publicat/ccdr-rmtc/15vol41/dr-rm41-02/ surv-2-eng.php.

4. Ebrahim M, Gravel D, Thabet C, Abdesselam K, Paramalingam $\mathrm{S}$, Hyson C. Antimicrobial use and antimicrobial resistance trends in Canada: 2014. Can Comm Dis Rep. 2016;42(11):22731. Available from: http://www.phac-aspc.gc.ca/publicat/ccdrrmtc/16vol42/dr-rm42-11/ar-02-eng.php.

5. Martin I, Sawatzky P, Liu G, Mulvey M. Antimicrobial resistance to Neisseria gonorrhoeae in Canada: 2009-2013. Can Comm Dis Rep. 2015;41(2). Available from: http://www.phac-aspc.gc.ca/ publicat/ccdr-rmtc/15vol41/dr-rm41-02/surv-4-eng.php.

6. Public Health Agency of Canada. Canadian Guidelines on Sexually Transmitted Infections - Gonococcal Infections Chapter [Internet]. Ottawa: PHAC; 2013 [updated 2014 Sep 26; cited 2016 May 3]. Available from: http://www.phac-aspc.gc.ca/std$\mathrm{mts} / \mathrm{sti}$-its/cgsti-ldcits/section-5-6-eng.php.

7. Pogany L, Romanowski B, Robinson J, Gale-Rowe M, LathamCarmanico C, Weir C. Management of gonococcal infection among adults and youth. Can Fam Physician. 2015;61(10):869.

8. Centers for Disease Control and Prevention. Update to CDC's sexually transmitted diseases treatment guidelines, 2010: oral cephalosporins no longer a recommended treatment for gonococcal infections. MMWR. 2015;61(31):590.

9. Furuya R, Koga Y, Irie S, Ikeda F, Kanayama A, Kobayashi I. In vitro activities of antimicrobial combinations against clinical 
isolates of Neisseria gonorrhoeae. J Infect Chemother. 2013;19(6):1218.

10. Hottes T, Lester R, Hoang L, McKay R, Imperial M, Gilbert M. Cephalosporin and azithromycin susceptibility in Neisseria gonorrhoeae isolates by site of infection, British Columbia, 2006 to 2011. Sexually Transm Dis. 2013;40(1):46.

11. Pereira R, Cole M, Ison C. Combination therapy for gonorrhoea: In vitro synergy testing. J Antimicrob Chemother. 2013;68(3):640.

12. Schumacher C, Ghanem K. Retreatment rates for uncomplicated gonorrhea infection: comparing ceftriaxone and azithromycin versus ceftriaxone and doxycycline. Sexually Transm Dis. 2013;40(7):539.

13. Singh AE Gratrix J, Martin I, Friedman D, Hoang L, Lester R, Metz G, et al. Gonorrhea treatment failures with oral and injectable expanded spectrum cephalosporin monotherapy vs. dual therapy at 4 Canadian sexually transmitted infection clinics, 2010-2013. Sexually Transm Dis. 2015;42(6).

14. Gratrix J, Bergman J, Anderson N, Read R, Singh A, Smyczek $P$ [Internet]. Adherence to new treatment guidelines for uncomplicated anogenital and pharyngeal Neisseria Gonorrhea cases in adults in Alberta, Canada. Meeting of the Infectious Diseases Society of America. 2014 [cited 2016 Dec 24]. Available from: https://www.researchgate.net/publication/267881937_ Adherence_to_New_Treatment_Guidelines_for_Uncomplicated_
Anogenital_and_Pharyngeal_Neisseria_Gonorrhea_Cases_in_ Adults_in_Alberta_Canada.

15. Lechtenberg R, Samuel M, Bernstein K, Lahiff M, Olson N Bauer $\mathrm{H}$. Variation in adherence to the treatment guidelines for Neisseria gonorrhoeae by clinical practice setting, California, 2009 to 2011. Sexually Transm Dis. 2014;42(6):331.

16. The Eastern European Sexual and Reproductive Health (EE $\mathrm{SRH}$ ) Network Antimicrobial Resistance Group. Recommended antimicrobial treatment of uncomplicated gonorrhoea in 2009 in 11 East European countries: implementation of a Neisseria gonorrhoeae antimicrobial susceptibility programme in this region is crucial. Sexually Transm Infect. 2010;86:442.

17. Roxanne K, Stenger M, Weinstock H, Berstein K, Reed M, Schumacher C. Gonorrhea treatment practices in the STD Surveillance Network, 2010-2012. Sexually Transm Dis. 2015;42(1):6.

18. Wetten S, Mohammed H, Yung M, Mercer C, Cassell J, Hughes G. Diagnosis and treatment of chlamydia and gonorrhoea in general practice in England 2000-2011: a population-based study using data from the UK clinical practice research datalink. BMJ Open. 2015.

19. Allen V, Mitterni L, Seah C, Anuradha R, Martin I, Lee C. Neisseria gonorrhoeae treatment failure and susceptibility to cefixime in Toronto, Canada. JAMA. 2013;309(2):163.

\section{Canadian Guidelines on Sexually Transmitted Infections}

\section{Mobile App Now Available}
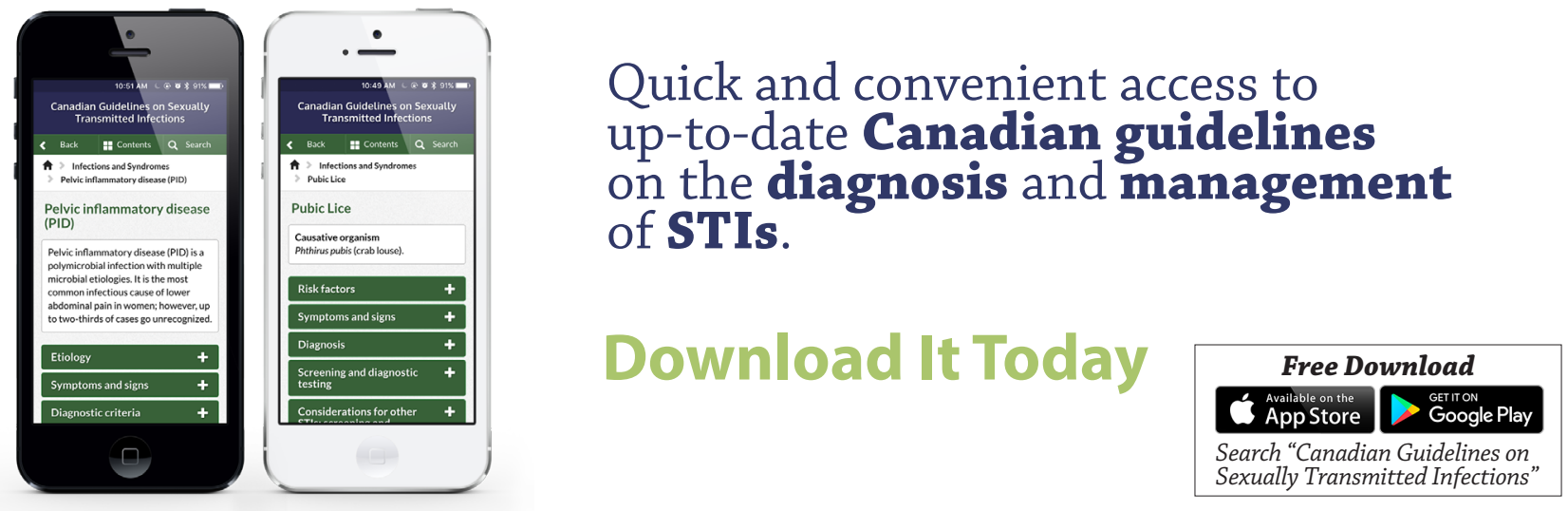

$\begin{array}{ll}\text { Public Health } & \text { Agence de la santé } \\ \text { Agency of Canada } & \text { publique du Canada }\end{array}$

Canadä 